\title{
Quantification of the daily dynamics of streamflow components in a small alpine watershed in Switzerland using end member mixing analysis
}

\author{
Kazi Rahman ${ }^{1,5}$ - Anne-Laure Besacier-Monbertrand ${ }^{1,2} \cdot$ Emmanuel Castella $^{1,2}$. \\ Brigitte Lods-Crozet $^{2,3} \cdot$ Christiane $\mathrm{Ilg}^{4} \cdot$ Olga Beguin $^{1,2}$
}

Received: 30 December 2014/ Accepted: 3 May 2015/Published online: 19 May 2015

(c) Springer-Verlag Berlin Heidelberg 2015

\begin{abstract}
There is a growing need to improve our understanding of catchment flow generation processes, especially in alpine watersheds, where the aquatic biodiversity is dependent upon the types of water sources and their seasonal dynamics. In order to identify and quantify the potential sources that contribute to stream runoff, Water samples were collected and discharge was measured. Other physical variables like electric conductivity and water temperature were also collected twice a day, once in the morning and once in the evening. These measurements continued for two to four consecutive days. In situ measurements were done for temperature, electric conductivity and turbidity of water at different temporal scale. Mass spectrometry was done to analyze silica and sulfate along with chlorine. Three different water sources were identified based on their physiochemical characteristics: glacier melt water, quickly routed surface runoff, and slowly routed ground water. Principal component analysis was performed in order to reduce dimensionality of the chemistry data
\end{abstract}

Electronic supplementary material The online version of this article (doi:10.1007/s12665-015-4505-5) contains supplementary material, which is available to authorized users.

\section{Kazi Rahman}

krahman@stanford.edu

1 Institute for Environmental Sciences, University of Geneva, Battelle. Building D, 7 route de Drize, 1227 Carouge, Switzerland

2 Forel Institute, University of Geneva, 10 route de Suisse, CP 416, 1290 Versoix, Switzerland

3 Musée cantonal de Zoologie, Lausanne, Switzerland

4 HEPIA Lullier, Jussy, Switzerland

5 Environmental Earth System Science, Stanford University, Stanford, CA, USA independently in two hydrological years. End member mixing analysis was carried out for morning and afternoon data to describe the daily variation of runoff components. Our study suggests that glacier melt component has a strong daily variation, which influences the magnitude and timing of peak flow. A sign of early melt and accumulation can be seen in this watershed based on the studied years.

Keywords EMMA - PCA - Glacier melt - Snow melt · Alps

\section{Introduction}

In glacial streams, physical constraints have critical influences on biodiversity, and especially upon the diversity, distribution and composition of macroinvertebrate communities. Discharge from different water sources (glacier melt, snow melt and groundwater) also play a significant role in shaping the invertebrate communities (Brown et al. 2010; Milner et al. 2009). Difficulties of field sampling and seasonal inaccessibility often limit our understanding of hydrological and biogeochemical process occurring in high elevation watersheds (Bales et al. 2006; Barthold et al. 2010). Especially, discharge measurement is challenging due to the irregular geometry of the riverbed. However, glaciers are shrinking, especially in the Swiss Alps, 84 out of 85 glaciers are having negative mass balance (WGMS, 2009), and the modification of their contribution to stream flow and environmental conditions is likely to alter running water biodiversity (Finn et al. 2010), prompting the need for a better understanding and modeling of water sources dynamics and stream flow generation.

End member mixing analysis (EMMA) (Christophersen et al. 1990; Hooper et al. 1990) is a multivariate analysis 
often used for tracer-based catchment stream flow separation analysis. EMMA is a widely accepted method for identifying water sources and their relative contribution to the stream discharge. It has been extensively applied for understanding streamflow generation process in small (Brown et al. 2006; Caine 1989; James and Roulet 2006; Liu et al. 2004) to large (Barthold et al. 2010) catchments and under various climatic conditions, including semi-arid seasonally snow-covered forested catchments (Liu et al. 2008). Studies reported about the applicability of EMMA in human influenced watersheds and discussed the limitations (Burns 2002). The application of EMMA depends on tracer selection, number of tracers and their conservative behavior of end members (i.e. sources). Guidelines are provided for possible tracer selection; outliers (when stream samples do not bound properly with the end members) in mixing diagram were explained in some studies (Barthold et al. 2010; Hooper 2001; Liu et al. 2008). End member mixing results can differ depending on the selected tracers and their number (Liu et al. 2004). In a snow and glacier dominated high altitude catchment, Brown et al. (2006) used EMMA to differentiate "quick flow" (dilute, rapidly routed melt water), "distributed flow" (sulfate-enriched, slow routed subglacial waters), and "groundwater" (silica-enriched groundwater). Few other studies reported a seasonal quantification of glacier melt to the stream flow (Cable et al. 2011).

Most studies were conducted to quantify hydrograph components at a daily time scale. However, the sub-daily temporal variability might have substantial significance in high altitude/glacial catchments. During the melt season, strong variations in temperature, sheer stress, suspended solid concentration and water chemistry might indeed occur at a sub-daily time scale and represent determinant constraints for the biota (Brittain and Milner 2001; Uehlinger and Malard 2003; Uehlinger et al. 2003; Ward 2004). Therefore, an attempt to quantify and model subdaily fluctuations of runoff contribution from various sources is a challenge for a better anticipation of biodiversity changes that might occur in glacier-fed streams. Temperature plays a very important role in melt process and the sub-daily variation of temperature will determine the melt rate which has consequence with the potential contribution of snow and glacier melt.

Therefore, the objective of this research was to quantify the contributing sources of stream flow generation and of their dynamics in a small high altitude catchment (Mutt catchment, upper Rhône basin, Switzerland) at a sub-daily time scale during the melt season. We focused on the applicability of EMMA technique for this watershed with relatively scarce data, because of limited accessibility during the year. We applied EMMA for two different time periods in order to assess relative changes between two hydrological years: 1997 and 2010. The specific research questions are: can EMMA be applied for such a watershed where the mixing dynamics is rapid due to steep slope. Can the contribution of each water sources be quantified? If yes, which one has the most dominating contribution? Is there any temporal trend of flow components between the study years?

\section{Study site}

The Mutt watershed, one of the head water of the Rhone basin $\left(46^{\circ} 62^{\prime} \mathrm{N}, 8^{\circ} 41^{\prime} \mathrm{E}\right)$, contains the Mutt glacier. It is located above the Gletsch hamlet in central Switzerland and contains both glaciated and unglaciated areas (Klok et al. 2001). The altitude ranges from $1757 \mathrm{~m}$ a.s.l. (gauging station Gletsch) to $3630 \mathrm{~m}$ a.s.1. (Dammastock) with a mean value of $2720 \mathrm{~m}$ a.s.l. The Mutt watershed covers an area of $7.06 \mathrm{~km}^{2}$ where $14 \%$ is glaciated. Areas located in high elevation zone are mostly covered with rock formation and the lower part is covered with vegetation (Lods-Crozet et al. 2001). This area is significantly important considering the river Rhone originates from this basin and it plays a critical role in biodiversity of this specific part of Switzerland.

The watershed is seasonally inaccessible. The reason of choosing this watershed is that it has a mixture of diverse water sources that generate stream runoff and it is not influenced by any dam of water diversion. Anthropogenic influences remain insignificant and the natural variability of flow can be depicted; moreover, a meteorological station (Grimsel, altitude $1980 \mathrm{~m}$ a.s.l., longitude $8^{\circ} 19^{\prime} 60^{\prime \prime}$ latitude $\left.46^{\circ} 34^{\prime} 18^{\prime \prime}\right)$ is located very close to the watershed and a continuous discharge measuring station (Gletsch, altitude $1716 \mathrm{~m}$ a.s.1., longitude $8^{\circ} 39^{\prime} 08^{\prime \prime}$, latitude $46^{\circ} 59^{\prime} 47^{\prime \prime}$ ) is located at its downstream point.

\section{Materials and methods}

\section{Hydrological and meteorological conditions}

Discharge data were collected from Federal Office for the Environment for the nearest gauging station 'Gletsch' to have better understanding of the relative changes in flow for the studied years (1997-2010). Together with discharge, precipitation and temperature data were collected to check for potential shifts between the studied years. Considering the melt season (April-October) reduction in peak flow and time shift can be seen (Fig. 1). The major differences between the 2 years occurred between July and October. Important decreases occurred from August to October, some being higher than $50 \%$. 


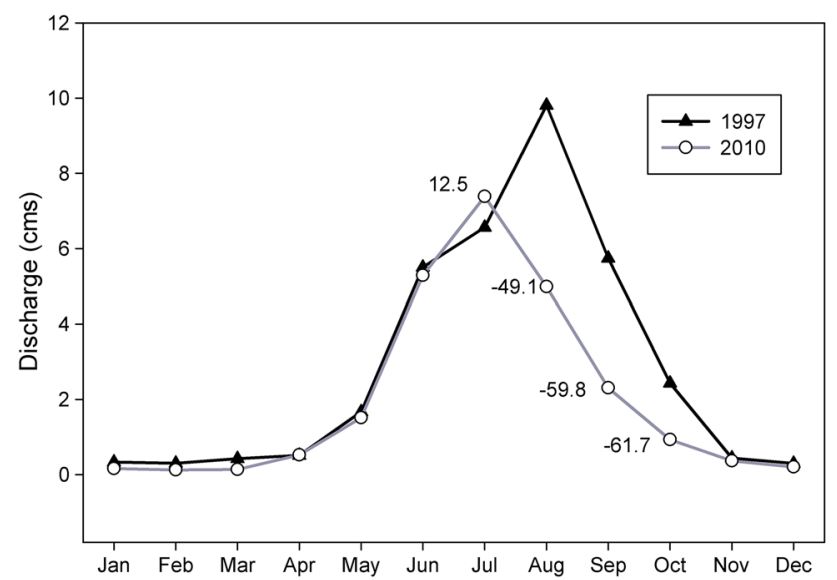

Fig. 1 Discharge comparisons between two hydrological years 1997 and 2010 at Gletsch gauging station (Rhone River). July and August indicate the percentage change of the most significant shifts

This reduction of flow can be of various reasons and most apparently because of precipitation and temperature changes. Therefore, precipitation and temperature data were analyzed from the Grimsel station (Fig. 2). Considering the relation between precipitation and temperature along with streamflow, it is visible that temperature plays a critical role in this basin (Fig. 1) since a larger portion is cover with snow. Particularly this notation can be seen in July as the amount to precipitation is low but streamflow is high in 2010 compared to 1997. This also reveals that the runoff behavior is dominated by temperature driven snow and glacier melt.

\section{Sampling stations}

Physical and chemical characteristics of water were measured at seven stations in the Mutt catchment: M1 and M4 on the main Mutt stream, T1-T5 in non-glacier-fed tributaries (Fig. 3). M1 is the most upstream station in the catchment, and the closest from the glacier front. It was considered to express the highest proportion of glacier melt contribution. M4 was the lowest point of the catchment where the mixing processes were measured and the water sources contribution calculated. T1-T5 tributaries were selected to depict various types of non-glacial water sources in the catchment. Snow samples were also collected to account for its contribution to the runoff.

\section{Field measurements and chemical analyses}

Because of limitations imposed by snow cover, water samples could only be collected between June and September. There were three measurement periods in 1997 (27-28 June, 8-11 August, 20-22 September) and two in 2010 (18-18 July, 4-8 September). Water samples were taken, discharge, water temperature and electrical conductivity measured twice a day at low (morning) and high (afternoon) discharges, for 2-4 consecutive days). Discharges were measured with depth/velocity transects. The bucket method was used for some small tributaries. Water samples were collected in plastic bottle and stored at $4{ }^{\circ} \mathrm{C}$ until analyzed. All water samples were filtered in the field through $0.45 \mu \mathrm{m}$ filters. Chloride $\left(\mathrm{Cl}^{-}\right)$and sulfate $\left(\mathrm{SO}_{4}{ }^{2-}\right)$ were examined by capillary electrophoresis. Silica was examined with the heteropoly blue method in a Hach spectrophotometer (Hach Company, Loveland, CO, USA). Snowmelt (high chloride, low silica), ice melt (low chloride and silica) and groundwater (high silica and sulfate) were supposed to be separated on the basis of these three elements, as suggested by previous studies undertaken under the AASER project (Brittain and Milner 2001; Brown et al. 2006).
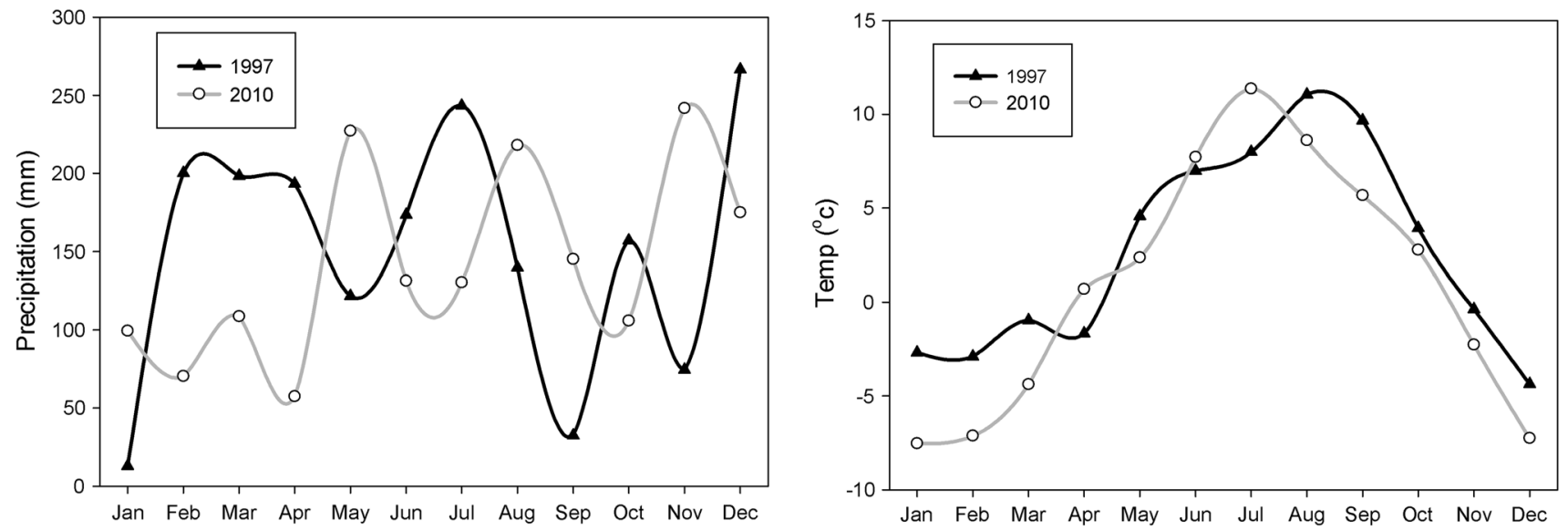

Fig. 2 Precipitation (monthly sum) and temperature (monthly mean) at the Grimsel meteorological station for the years 1997 and 2010 


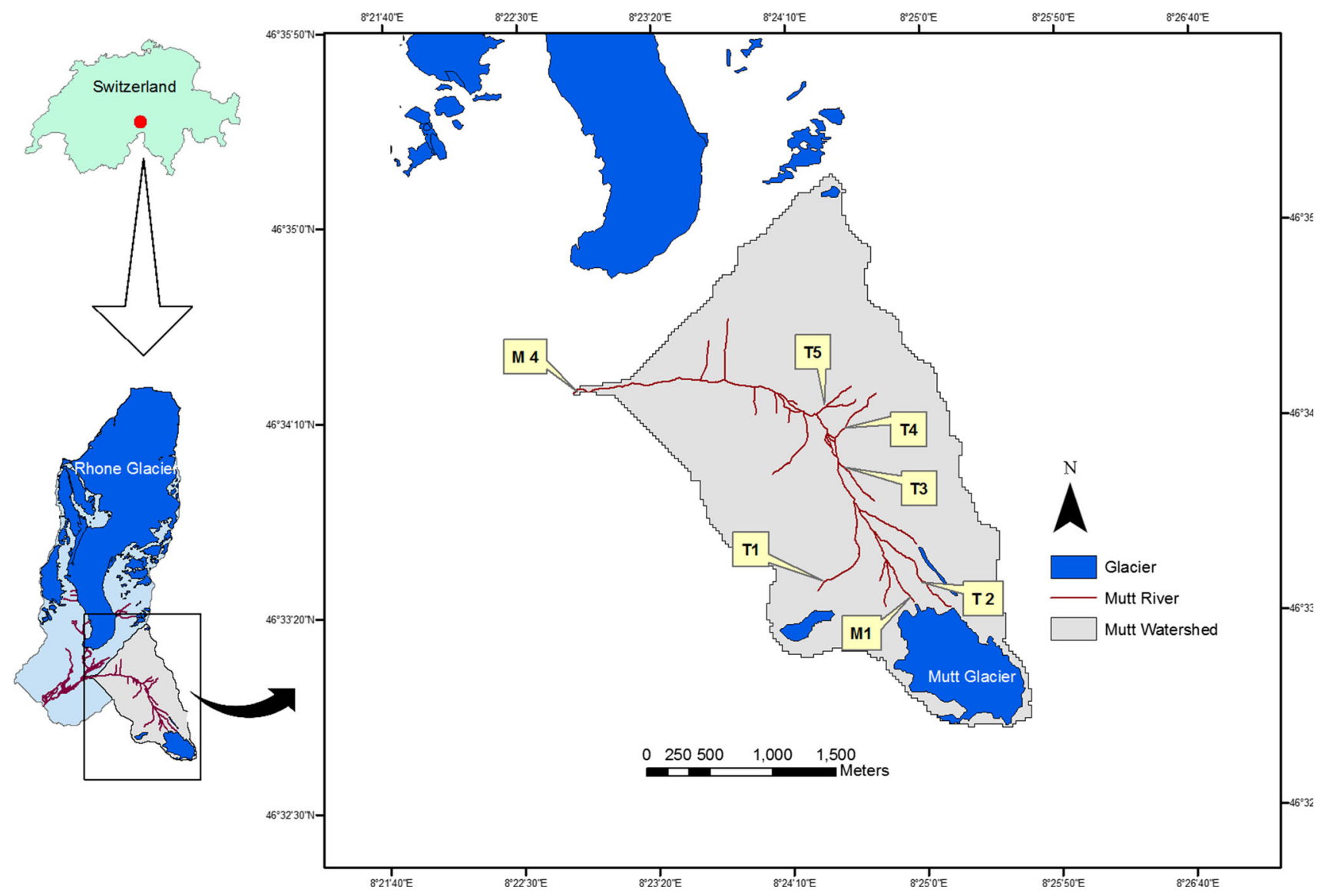

Fig. 3 Study area, showing the Mutt catchment. Yellow squares with codes indicate the sampling stations

\section{Mixing model analysis}

\section{End member mixing analysis}

EMMA is based on the assumption that stream water chemistry is composed of a set of end members that have distinct chemical signatures (Christophersen et al. 1990; Hooper et al. 1990; Liu et al. 2008). End members are basically sources that contribute to the streamflow (Neill et al. 2011). In the ideal condition the stream water samples should be bound by the median values of the end members (i.e. the median values of tracers of the end members). As a first step, end members should be selected by their chemical signature. The chemical signature should be defined by a combination of tracers. Tracers are conservative, which means that no chemical reactions can occur that would modify their concentration All end members have significantly different concentrations for at least one tracer. End members are often considered as components by some authors (Liu et al. 2004) until the end member selection is not confirmed. The eligibility of end members will be confirmed with the mix diagram. Tracers (chemical signature of samples) play an important role in end member eligibility criteria section. Tracer concentrations in all components are considered temporally constant or having known variations. Tracer concentrations in all end members are considered spatially constant or treated as different components. Unmeasured components are regarded as having the same tracer concentrations or as contributing insignificantly. End members can be determined based on an Eigen vector analysis, such as principal component analysis (PCA). Based on the determined end members, their contributions can be calculated as a function of their chemical composition.

\section{Hydrograph separation}

A PCA was used to reduce the dimensionality of the water samples by tracer's data set and to determine the end members. PCA was used to identify 'lower dimensional' space often call $U$ space. The so called $U$ space, in which the stream water observations lies, that describes the variability of the data set. We followed the procedure described (Barthold et al. 2011; Hooper et al. 1990; Neill et al. 2011), where the mixing point stream concentration values $(n)$ for the solute $(p)$ were standardized by centering 
them about their means and diving by the standard deviation. Similarly median of the concentration of end members was also standardized. After this transformation, both standardized stream data and end member medians were projected on to the $m$-dimensional $U$ space by the orthogonal projection

$U=X V^{T}$

where $U$ is the resultant data matrix of $n * m, X$ is $n * m$ standardized data matrix and $V$ is the $m^{*} p$ matrix of retained Eigen vector obtained from PCA. The fraction of the identified end members in each stream water sample was then calculated by solving the following set of linear equations.

$$
\begin{aligned}
& 1=x+y+z \\
& \mathrm{SW}_{U 1}=x \mathrm{EM}_{1 U 1}+y \mathrm{EM}_{2 U 1}+z \mathrm{EM}_{3 U 1} \\
& \mathrm{SW}_{U 2}=x \mathrm{EM}_{1 U 2}+y \mathrm{EM}_{2 U 2}+z \mathrm{EM}_{3 U 2}
\end{aligned}
$$

where $x, y, z$ are the unknown fraction of each end member; $\mathrm{SW}_{U 1}$ and $\mathrm{SW}_{U 2}$ are projected stream water observation in $U$ space, $\mathrm{EM}_{n U 1}$ and $\mathrm{EM}_{n U 2}$ are the nth end member coefficient in $U$ space. This set of equations is an example for a three end member problem. It can be extended or reduced for larger or smaller sized end member problems. Tables 1 and 2 list the observation data and the calculations are provided as supplementary document (EMMA calculations). Table 3 presents the cumulative Eigen vector percentages for both the year studied.

\section{Results}

\section{Statistical analysis}

Statistical analysis was done to characterize the water sources based on water sample collected from different sampling points with their chemical composition based on the hydro chemical characteristics. Since temperature poses various energy gains and losses, it was taken apart from the multivariate analysis. Turbidity and electric conductivity were excluded from the multivariate analysis because the electric conductivity has influence on the total ions of the solution. PCA was done independently for both study years in order to understand changes happened due to different weather conditions. All the calculations were performed using MATLAB and crosschecked with the statistical open source software package $\mathrm{R}$ version 2.13.1 in Eigen vector calculation. Based on the site specific knowledge and physico chemical characteristics T5 and T4 were considered as 'gradual flow' occurring due to slow routed ground water. Together with the physical variables like temperature and conductivity, T4 and T5 pose higher values of $\mathrm{Si}$ and $\mathrm{SO}_{4}{ }^{2-}$ compared to the other sites (Fig. 4) whereas T1, T2, T3 were considered into slow routed gradual water flow coming mostly from snow melt and precipitation. M1 considered as glacier melt sources. T4 and T5 were considered as ground water fed tributaries since they have closer values of $\mathrm{Si}$ and $\mathrm{SO}_{4}{ }^{2-}$ concentration

\begin{tabular}{|c|c|c|c|c|c|c|c|c|}
\hline Station & Date & Mor/eve & Temp $\left({ }^{\circ} \mathrm{C}\right)$ & Cond $(\mu \mathrm{S} / \mathrm{cm})$ & $\mathrm{SO}_{4}{ }^{2-}(\mathrm{mg} / \mathrm{l})$ & $\mathrm{Cl}(\mathrm{mg} / \mathrm{l})$ & $\mathrm{Si}(\mathrm{mg} / \mathrm{l})$ & Discharge $\left(\mathrm{m}^{3} / \mathrm{s}\right)$ \\
\hline M4 & $6 / 27 / 1997$ & Morning & 3.6 & 144 & 22.32 & 0.39 & 1.18 & NA \\
\hline M4 & $6 / 27 / 1997$ & Evening & 4.6 & 130 & 24.16 & 0.51 & 1.03 & NA \\
\hline M4 & 6/28/1997 & Morning & 4.5 & 132 & 24.03 & 0.47 & 1.41 & 0.75 \\
\hline M4 & $6 / 28 / 1997$ & Evening & 5.8 & 115 & 21.62 & 0.35 & 1.13 & NA \\
\hline M4 & 8/8/1997 & Evening & 10.7 & 103.8 & 16.46 & 1.37 & 0.56 & 0.47 \\
\hline M4 & 8/9/1997 & Morning & 6.4 & 76.6 & 20.26 & 0.89 & 0.71 & 0.67 \\
\hline M4 & 8/9/1997 & Evening & 10.3 & 66 & 14.31 & 0.21 & 0.71 & 0.94 \\
\hline M4 & 8/10/1997 & Morning & 7.7 & 78 & 19.91 & 0.48 & 1.69 & 0.92 \\
\hline M4 & 8/10/1997 & Evening & 10.1 & 67 & 14.85 & 0.44 & 0.8 & 1.25 \\
\hline M4 & 8/11/1997 & Morning & 7 & 75 & 19.06 & 0.63 & 0.8 & 0.7 \\
\hline M4 & 9/20/1997 & Morning & 6.1 & 171 & 14.56 & 0.2 & 1.11 & 0.18 \\
\hline M4 & 9/20/1997 & Evening & 8.2 & 114.3 & 4.56 & 0.04 & 0.56 & 0.3 \\
\hline M4 & 9/21/1997 & Morning & 5.2 & 165 & 23.56 & 0.21 & 1.18 & 0.18 \\
\hline M4 & 9/21/1997 & Evening & 10.4 & 145 & 15.35 & 0.17 & 0.64 & 0.27 \\
\hline M4 & $9 / 22 / 1997$ & Morning & 6.2 & 168.2 & 21.42 & 0.22 & 1.19 & 0.18 \\
\hline M4 & 9/22/1997 & Evening & 7.6 & 124 & 12.39 & 0.14 & 0.79 & 0.25 \\
\hline
\end{tabular}

Table 1 Physicochemical characteristics of the Mutt River water at station M4, where mixing components are calculated for the hydrological year 1997 
Table 2 Physicochemical characteristics of the Mutt River water at station M4, where mixing components are calculated for the hydrological year 2010

\begin{tabular}{lllllllll}
\hline Station & Date & Mor/eve & Temp $\left({ }^{\circ} \mathrm{C}\right)$ & Cond $(\mu \mathrm{S} / \mathrm{cm})$ & $\mathrm{SO}_{4}{ }^{2-}(\mathrm{mg} / \mathrm{l})$ & $\mathrm{Cl}(\mathrm{mg} / \mathrm{l})$ & $\mathrm{Si}(\mathrm{mg} / \mathrm{l})$ & $\mathrm{Discharge}\left(\mathrm{m}^{3} / \mathrm{s}\right)$ \\
\hline M4 & $7 / 16 / 2010$ & Morning & 11.9 & 121.7 & 24 & 0.19 & 27.5 & 0.57 \\
M4 & $7 / 16 / 2010$ & Evening & 13.3 & 110 & 20 & 0.19 & 79.6 & 0.72 \\
M4 & $7 / 17 / 2010$ & Morning & 9.9 & 120 & 21 & 0.2 & 47.4 & 0.57 \\
M4 & $7 / 17 / 2010$ & Evening & 12.5 & 111.1 & 21 & 0.19 & 64.6 & 0.67 \\
M4 & $7 / 18 / 2010$ & Morning & 5.9 & 130.1 & 18 & 0.23 & 15.2 & 0.7 \\
M4 & $9 / 4 / 2010$ & Evening & 12.4 & 194.4 & 41 & 0.94 & 4.5 & 0.29 \\
M4 & $9 / 5 / 2010$ & Morning & 7.3 & 192.6 & 22 & 0.9 & 4.2 & 0.39 \\
M4 & $9 / 5 / 2010$ & Evening & 11.7 & 193.9 & 44 & 1.26 & 7.8 & 0.38 \\
M4 & $9 / 6 / 2010$ & Morning & 6.5 & 193 & 188 & 43 & 4.11 & 8.6 \\
M4 & $9 / 6 / 2010$ & Evening & 9.4 & 174 & NA & NA & 11.1 & 0.42 \\
M4 & $9 / 7 / 2010$ & Morning & 6.9 & 153.1 & NA & 36.3 & 0.47 \\
M4 & $9 / 8 / 2010$ & Evening & 8.1 & NA & NA & 26 & 0.69 \\
M4 & $9 / 8 / 2010$ & Evening & 7.7 & 158.9 & & & NA \\
\hline
\end{tabular}

Table 3 Eigen vectors for the hydrological year 1997 and 2010

\begin{tabular}{llll}
\hline Year & Mor/eve & $U 1$ & $U 2$ \\
\hline 1997 & Morning & 50.21 & 84.79 \\
& Evening & 51.48 & 93.38 \\
2010 & Morning & 69.37 & 92.06 \\
& Evening & 98.124 & 99.95 \\
\hline
\end{tabular}

(Fig. 4) also reflected similar nature of electric conductivity.

\section{Mixing model result}

In the Fig. 5, stream water samples collected at the downstream station M4 are represented together with the water sources selected within the catchment (i.e. the end members). The dot points represent the stream water sample (at M4) and the error bars ( \pm 1 SD) represent the median concentration of end members. The error bars are significantly smaller in 1997 compared to 2010; however, T3, T4 and M1 represent the best bound for the M4 stream samples. Water sample from M1 represents glacier melt with the lowest silica and $\mathrm{SO}_{4}{ }^{2-}$ concentrations, whereas T4 and T5 have higher $\mathrm{SO}_{4}{ }^{2-}$ and silica concentrations but their silica concentration differs slightly (based on Tables 1, 2). T3 contains the highest amount of silica. The T3-T5 stations contain mineralized water (conductivity values relatively higher) reflecting the influence of a carbonated outcrop crossing the catchment in its central part (Lods-Crozet et al. 2001).

Table 3 describes the cumulative Eigen vector percentage in two axes, since the total variability is explained more than $80 \%$ it is decent enough to take three end members

\section{Hydrological year 1997}

In total seven observations were taken in the morning and six were taken in the evening in the melt season of 1997. It is important to mention that the study site is seasonally inaccessible and some tributaries are located at high altitude where the vehicle facility is not available. The measured values of physical and chemical components are represented in the Tables 1 and 2. Considering the mix diagram, Fig. 6a, b, in the morning session it is clearly visible that the stream water sample (at M4) is properly bounded by the end members (or sources). Therefore, the end member selection can also be validated with this diagram. Considering the contributions of sources, there is a combination of all the sources that contributes stream runoff based on the observation days. It should be noted that the flow is relatively smaller in the September compared to August in both morning and evening which is correlated with the mean temperature of nearest station (Fig. 2). One important thing can be seen that the glacier melt component varies from morning to evening and the evening contribution is higher compared to morning. This is possibly due to intensity of solar radiation; however, the sub-daily scale solar radiation data was not possible to get from the exact location because of physical constrain.

\section{Hydrological year 2010}

Five observations were done in the morning and six observations were done in the afternoon in the 

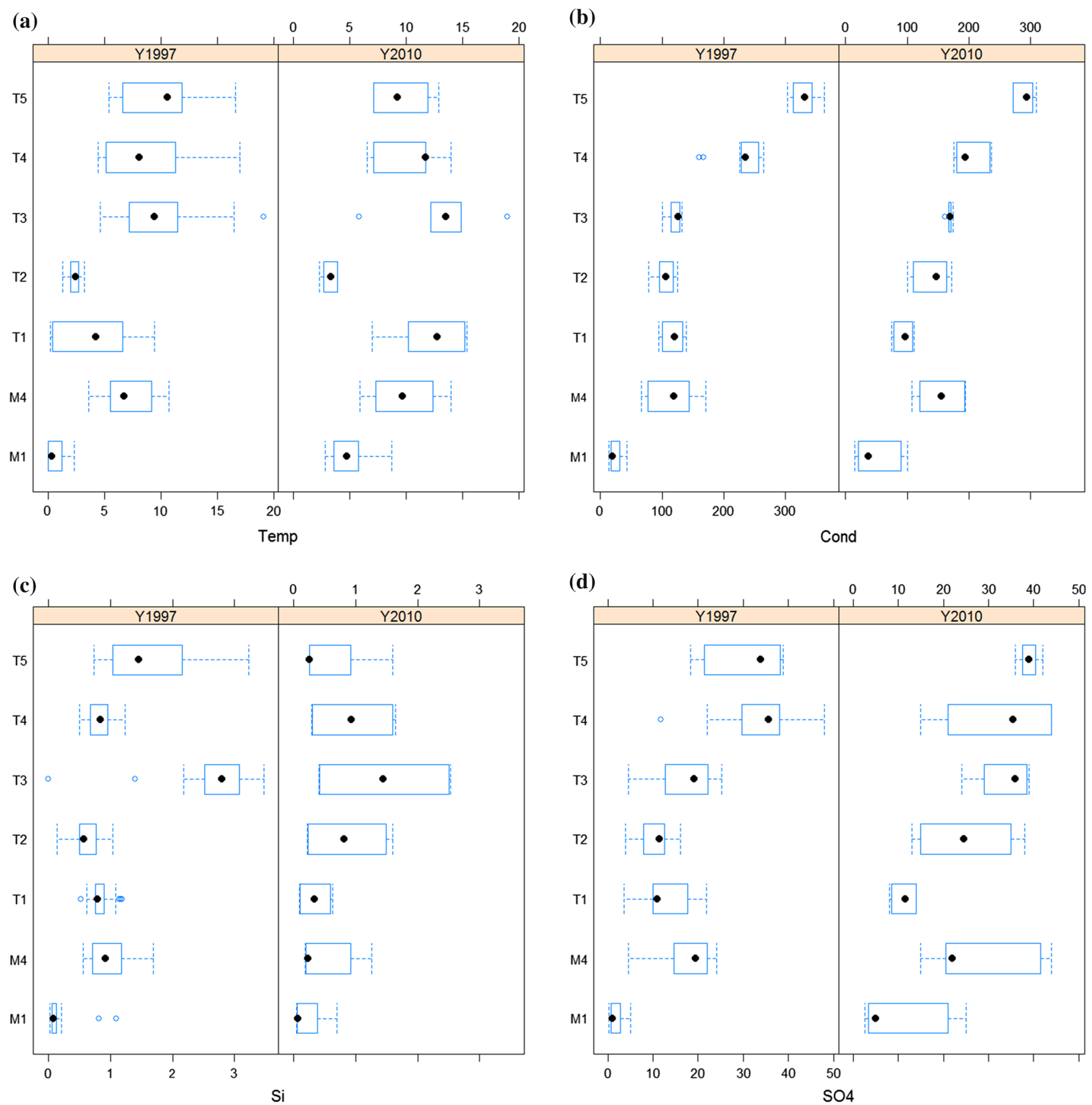

Fig. 4 Variability of temperature (a), conductivity (b), silica (c) and $\mathrm{SO}_{4}{ }^{2-}$ (d) in the Mutt and its tributaries for the hydrologic years 1997 and 2010

hydrological year 2010. Some outliers are visible in the mix diagram of morning data which can be of various reasons. These outliers are mostly correlated with field sampling. Considering the contribution from the different sources the highest proportion is coming from glacier melt in the morning session. One important signal can be noticed with the comparison of morning and evening in the glacier melt proportion. The glacier melt contribution no longer exists in the evening session. This is probably because of early starts of snow accumulation process. There were two observations in the late summer for both morning and evening sessions (i.e. 5th and 6th September) where the glacier melt has very little contribution in the morning as compared to the other observations in the 

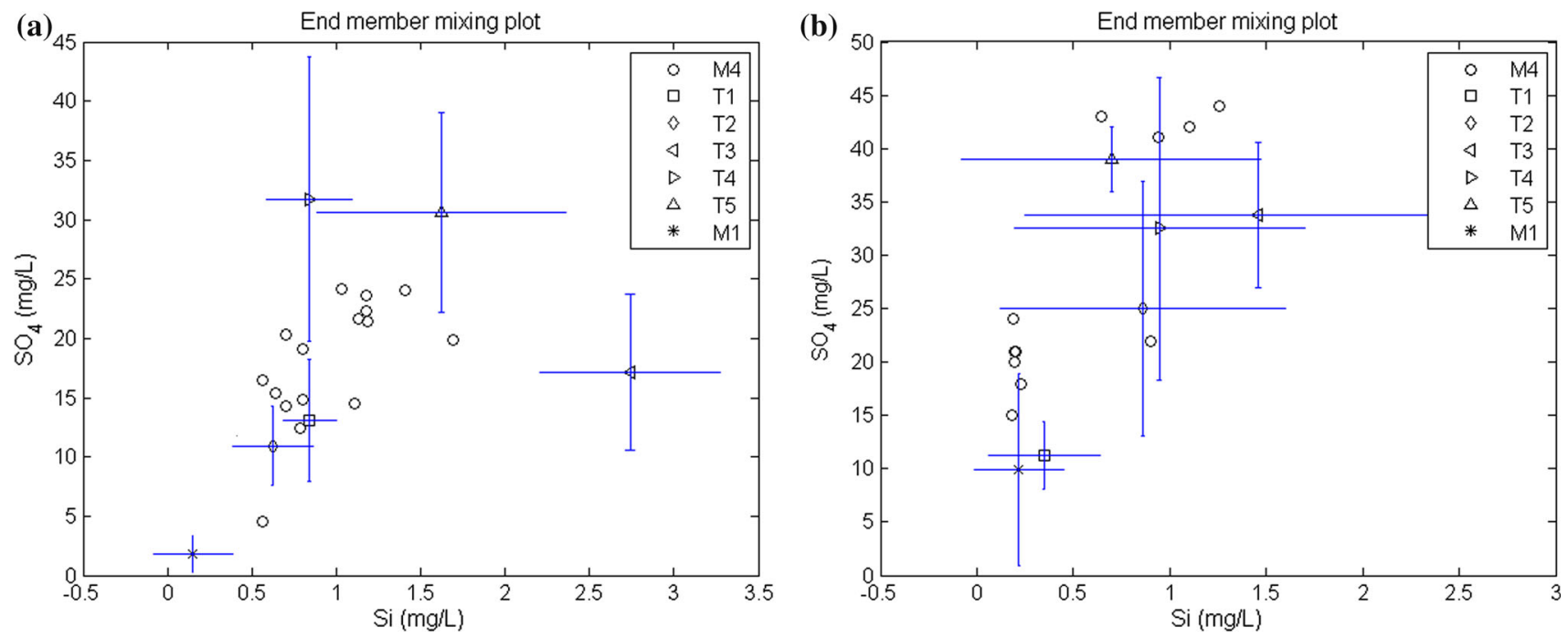

Fig. $5 \mathrm{Si} \mathrm{vs} \mathrm{SO}_{4}{ }^{2-}$ diagram showing the M4 downstream station and the other stations reflecting potential water sources for the hydrologic year 1997 (a) and 2010 (b)

(a)

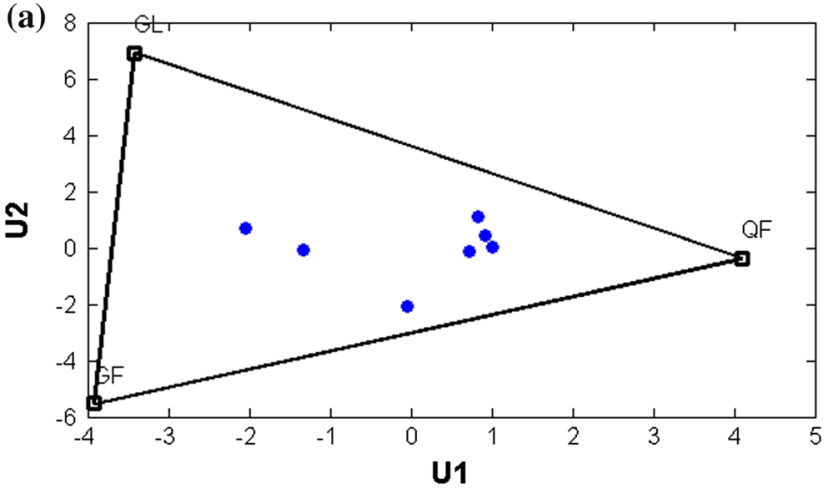

(b)

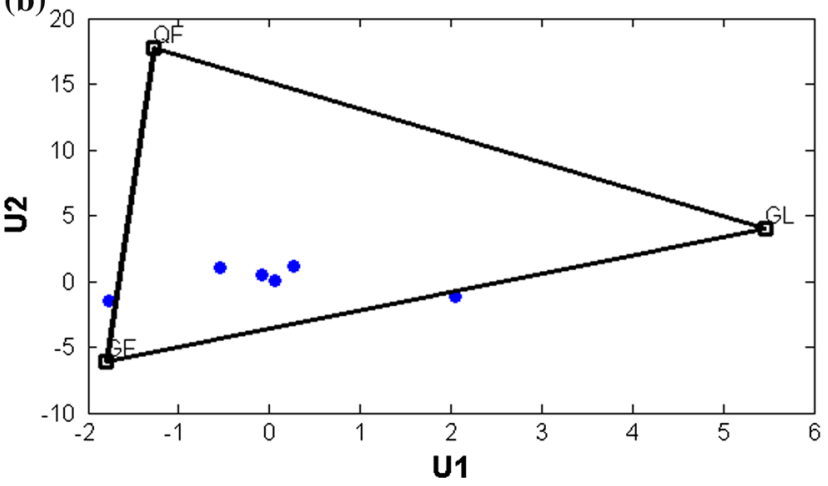

Fig. $6 U$ space mix diagram for hydrological year 1997 and 2010. a Morning 1997, b evening 1997, c morning 2010 and d evening 2010. The blue dots represent the water samples taken at station M4,

same period. This is a signal of melt process contribution reductions in the late summer. Also zero contribution in the evening reveals that in the late summer melt process occurs mostly in the morning.
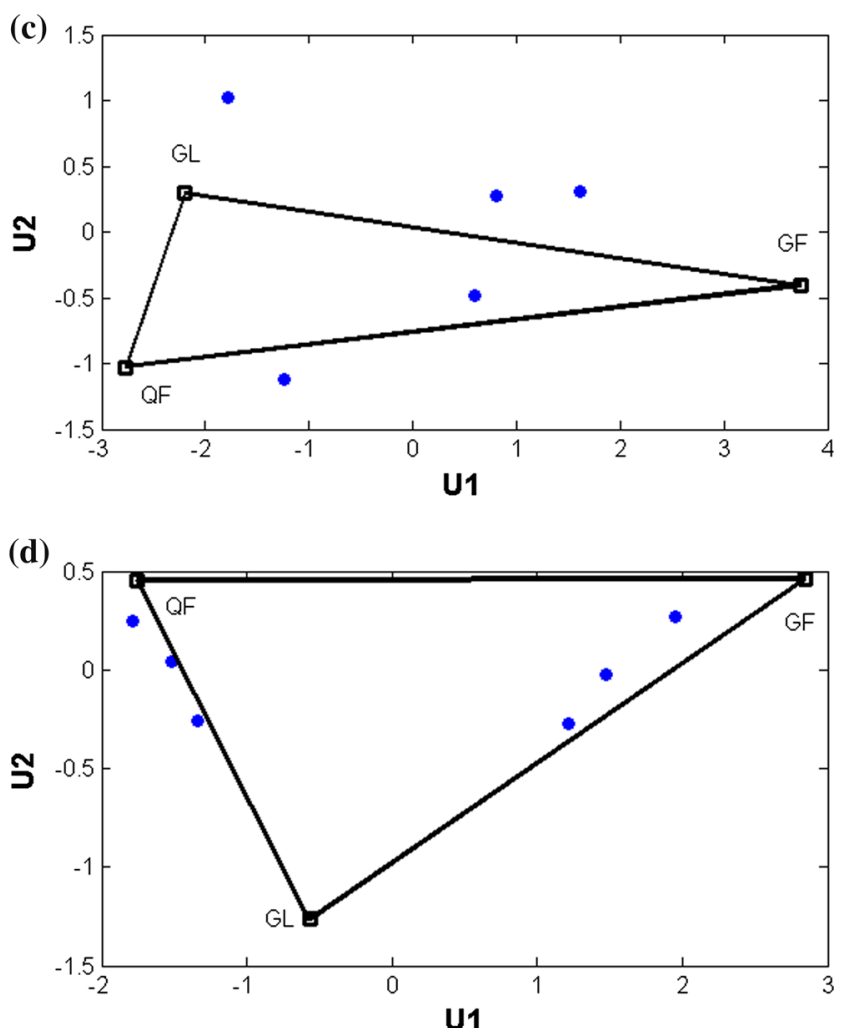

where corners of the triangles are the median value of end members. $G L, G F$ and $Q F$ indicate glacial flow, ground water flow and rainfall driven quick flow

\section{Comparison between the two hydrological years}

In the years studied, some similarities and discrepancy can be seen considering average discharge and 
contribution from individual end member contribution. The average discharge was higher in August and lower in September, which we can consider as raising and recession period. Similarities can be seen during the raising period of melt (until august) as the glacier melt component changes quickly. It is clearly visible that the glacier melt increases (yellow marked in Fig. 7) from morning to evening in both the studied years. However, quick flows are not present in all the events as they are linked with temperature and precipitation. Glacier melt flows also varies as we can see in the afternoon measurements of September 2010 where there is no noticeable contribution of glacier melt. This is probably due to snow accumulation process that starts earlier which is also apparent as the total discharge has smaller values than the raising period considering raising period until August based on the Fig. 2.

\section{Discussion}

Our results show that contribution from end members varies along with time, even in the instantaneous day of a melting season the contribution can be different in morning and evening. This can be seen if we consider the melt season of the two groups; an increasing trend of glacier flow can be seen from morning to evening until August. The reason of
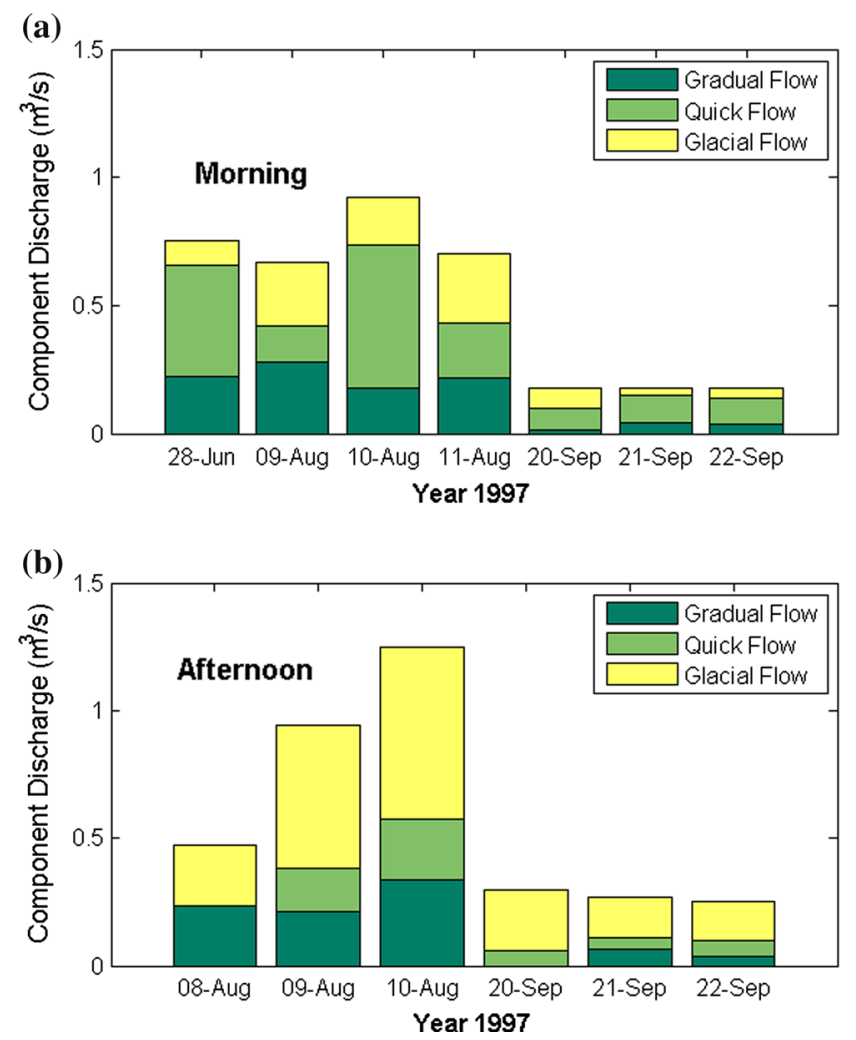

choosing two different years is to address if there is any changes occurred in the catchment flow generation process. The variability can be observed in the glacier melt contribution; comparing 1997 and 2010 based on Fig. 6, we can see that glacier melt decreases in September 2010, which physically means that the snow accumulation process happened earlier than 1997.

However, several uncertainties can be arise due to sampling process. Precision and accuracy related to stream chemistry measurement have a significant importance in EMMA, if the chemical composition is not measured with proper precision it may lead to uncertainty which will affect the flow partitioning. In a study, Soulsby et al. (2003) calculated by mass balance that sub-surface water contributed $6 \%$ of total flow in a stream. The calculated contribution could, however, be as much as $17 \%$ if the measured stream chemical compositions were adjusted by typical measurement error. Non-conservative solute behavior, unidentified end members, and temporal variability of end members could also cause additional uncertainty. Besides these, more fundamental source of uncertainty in mass balance approaches to stream flow partitioning may arise from the trouble in reliably characterizing end member properties, even where the end members are appropriately identified. Several studies have suggested and described solutions of uncertainties in
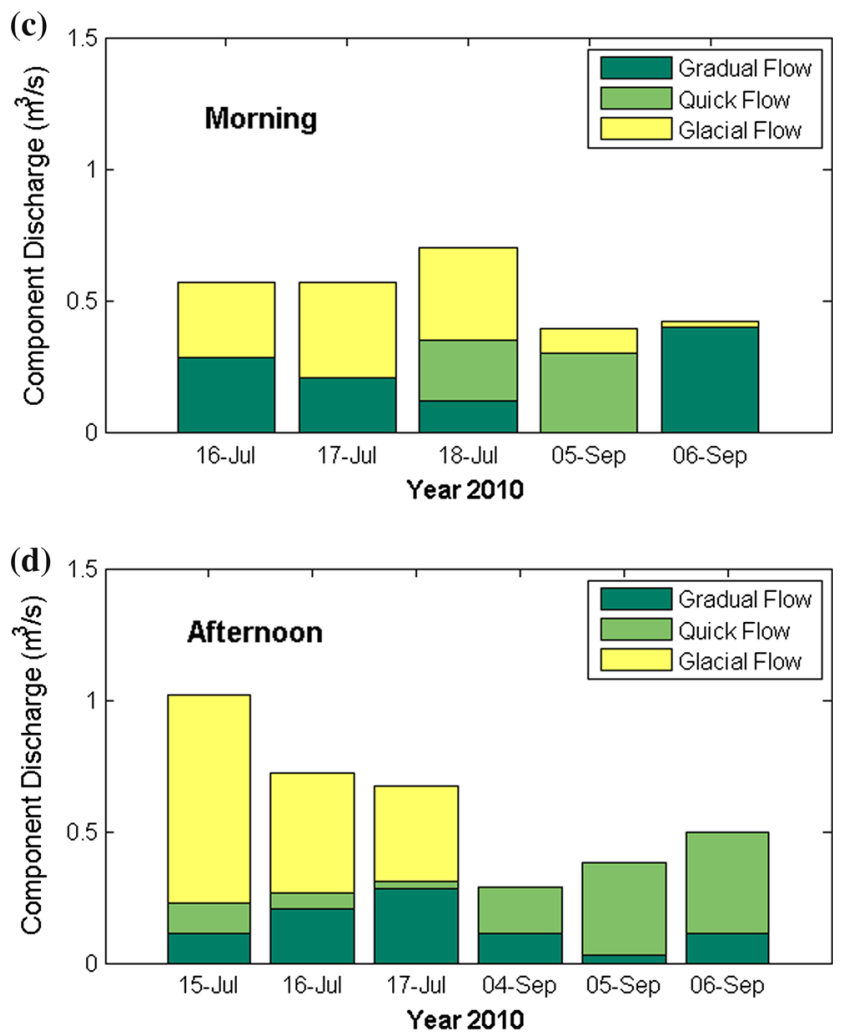

Fig. 7 Flow components for the hydrological years 1997 and 2010, a morning 1997, b evening 1997, c morning 2010 and d evening 2010 
application of EMMA (Christophersen and Hooper 1992; Liu et al. 2004, 2008). Usually these 'outliers' cause systematic high and low estimation when calculating the contributions of the end members.

Another issue often discussed in the EMMA analysis is about grouping of samples with respect to tracer selection. The first question may arise as to how many tracers we need to perform EMMA analysis (Barthold et al. 2011). What are the conditions that the tracers need to fulfill and what are the criteria we set for selecting the tracers. Studies conducted by Barthold et al. (2011) concluded that tracers are different with the different watershed, based on geology. Here we used silica and $\mathrm{SO}_{4}{ }^{2-}$ as main chemical indicator following the literature by Brown et al. (2006) considering similar physiographic condition of mountainous watershed. Based on the solute vs solute diagram with silica and $\mathrm{SO}_{4}{ }^{2-}$ we can see the variability is higher in 2010 compared to 1997 that stream sample is well explained considering M4 as combined stream sample.

Two main signals can be detected from this study, they are the fluctuation of glacier melt component and magnitude. Shifting behavior of glacial flow in 2010 is linked with the temperature change (Fig. 2). The measurement was taken in September. A comparison of the temperature shift between 1997 and 2010 influenced the melting process. However, this comparison can be statistically insignificant because of data for only 2 years, but considering the accessibility our objective was to see the sign of melting process. Overall, the major changes can be seen in the glacier melt contribution as the large portion in July was from glacier melt but in September it became insignificant

Some studies have been conducted in sub-daily scale to understand the sediment flux in the mountainous basins with the objective of land conservation (Duvert et al. 2011). Sediments are important to understand nutrients transport and soil loss process; the results showed that sub-daily fluctuations are highly correlated with the catchment size land-use type and gradient of the watershed. However, no study so far been reported on sub-daily contribution of streamflow component. Similarly daily discharge fluctuation has been studied by Collins (1995) focusing discharge, solute content, and solute flux, in Findelengletscher and Gornergletscher, Kanton Wallis, Switzerland. Result suggests that net reaction rate is faster and that the rates of decrease of average transit time of melt water with discharge are less rapid beneath Findelengletscher. Also, the melt rate fluctuations are correlated with environmental variables like temperature, slope of watershed etc. Therefore, our results will provide an added value on sub-daily dynamics of flow component contribution.

\section{Conclusions}

Mountain glacier dominated streams pose a strong variability of discharge due to environmental variables like solar radiation, wind speed, relative humidity the variation has a significant influence for the invertibribate living in the different types of water. Therefore, identification and quantification of discharge component have an important role of the living organisms. The overall objective was to analyze the stream flow component based on physicochemical constrains using EMMA, and we found stream runoff can be explained as a function of end members. Based on the variability explained EMMA can be applicable to clarify the identification of geographic runoff sources. According to the physical and chemical characteristics three major sources were identified as providing stream runoff in the Gletsch watershed; they are glacier melt, quick routed surface runoff and slow routed ground water. Daily dynamics of the water reveals that during rising period of the melt season glacier melt contribution is higher (until August) in the evening, but slower in the late period. Our analysis was limited to summer melt due to inaccessibility of the watershed; moreover, the flow generation process is significantly important in the melting season which occurs during the summer period. Comparing two hydrological years 1997 and 2010, it can be concluded that the flow regime is changing based on the contribution of glacier melt water. Information gained from this study will be used to analyze the ecological connectivity of species living in the watershed, their dependency of the type of water as a future step.

Acknowledgments This research was funded by the 7th framework program of European Commission Project ACQWA (Assessing Climate Change Impact on Water Quantity and Quality) under Contract No. 212250 (http://www.acqwa.ch). Part of the data used for this study (hydrologic year 1997) from the EU project AASER. Financial support from the SNSF postdoc mobility program (Project Code P2GEP2_148530) is also acknowledged.

\section{References}

Bales RC, Molotch NP, Painter TH, Dettinger MD, Rice R, Dozier J (2006) Mountain hydrology of the western United States. Water Resour Res 42(8)

Barthold FK, Wu JK, Vache KB, Schneider K, Frede HG, Breuer L (2010) Identification of geographic runoff sources in a data sparse region: hydrological processes and the limitations of tracer-based approaches. Hydrol Process 24(16):2313-2327

Barthold FK, Tyralla C, Schneider K, Vache KB, Frede H-G, Breuer L (2011) How many tracers do we need for end member mixing analysis (EMMA)? A sensitivity analysis. Water Resour Res 47

Brittain JE, Milner AM (2001) Ecology of glacier-fed rivers: current status and concepts. Freshw Biol 46(12):1571-1578 
Brown LE, Hannah DM, Milner AM, Soulsby C, Hodson AJ, Brewer MJ (2006) Water source dynamics in a glacierized alpine river basin (Taillon-Gabietous, French Pyrenees). Water Resour Res 42(8)

Brown LE, Milner AM, Hannah DM (2010) Predicting river ecosystem response to glacial meltwater dynamics: a case study of quantitative water sourcing and glaciality index approaches. Aquat Sci 72(3):325-334

Burns DA (2002) Stormflow-hydrograph separation based on isotopes: the thrill is gone-what's next? Hydrol Process 16(7):1515-1517

Cable J, Ogle K, Williams D (2011) Contribution of glacier meltwater to streamflow in the Wind River Range, Wyoming, inferred via a Bayesian mixing model applied to isotopic measurements. Hydrol Process 25(14):2228-2236

Caine N (1989) Hydrograph separation in a small alpine basin based on inorganic solute concentrations. J Hydrol 112(1-2):89-101

Christophersen N, Hooper RP (1992) Multivariate-analysis of stream water chemical-data-the use of principal components-analysis for the end-member mixing problem. Water Resour Res 28(1):99-107

Christophersen N, Neal C, Hooper RP, Vogt RD, Andersen S (1990) Modeling stream water chemistry as a mixture of soil water end members-a step towards 2nd generation acidification models. J Hydrol 116(1-4):307-320

Collins DN (1995) Daily patterns of discharge, solute content and solute flux in meltwaters draining from two alpine glaciers. In: IAHS publications-series of proceedings and reports-intern assoc hydrological sciences, vol 228, pp 371-378

Duvert C, Gratiot N, Nemery J, Burgos A, Navratil O (2011) Subdaily variability of suspended sediment fluxes in small mountainous catchments-implications for community-based river monitoring. Hydrol Earth Syst Sci 15(3):703-713

Finn DS, Raesaenen K, Robinson CT (2010) Physical and biological changes to a lengthening stream gradient following a decade of rapid glacial recession. Glob Chang Biol 16(12):3314-3326

Hooper RP (2001) Applying the scientific method to small catchment studies: a review of the Panola Mountain experience. Hydrol Process 15(10):2039-2050

Hooper RP, Christophersen N, Peters NE (1990) Modelling streamwater chemistry as a mixture of soilwater end-members-an application to the Panola Mountain catchment, Georgia, USA. J Hydrol 116(1-4):321-343
James AL, Roulet NT (2006) Investigating the applicability of endmember mixing analysis (EMMA) across scale: a study of eight small, nested catchments in a temperate forested watershed. Water Resour Res 42(8)

Klok EJ, Jasper K, Roelofsma KP, Gurtz J, Badoux A (2001) Distributed hydrological modelling of a heavily glaciated Alpine river basin: hydrological Sciences Journal. J Des Sci Hydrol 46(4):553-570

Liu FJ, Williams MW, Caine N (2004) Source waters and flow paths in an alpine catchment, Colorado Front Range, United States. Water Resour Res 40(9)

Liu FJ, Bales RC, Conklin MH, Conrad ME (2008) Streamflow generation from snowmelt in semi-arid, seasonally snowcovered, forested catchments, Valles Caldera, New Mexico. Water Resour Res 44(12)

Lods-Crozet B, Castella E, Cambin D, Ilg C, Knispel S, MayorSimeant H (2001) Macroinvertebrate community structure in relation to environmental variables in a Swiss glacial stream. Freshw Biol 46(12):1641-1661

Milner AM, Brown LE, Hannah DM (2009) Hydroecological response of river systems to shrinking glaciers. Hydrol Process 23(1):62-77

Neill C, Chaves JE, Biggs T, Deegan LA, Elsenbeer H, Figueiredo RO, Germer S, Johnson MS, Lehmann J, Markewitz D, Piccolo MC (2011) Runoff sources and land cover change in the Amazon: an end-member mixing analysis from small watersheds. Biogeochemistry 105(1-3):7-18

Soulsby C, Petry J, Brewer MJ, Dunn SM, Ott B, Malcolm IA (2003) Identifying and assessing uncertainty in hydrological pathways: a novel approach to end member mixing in a Scottish agricultural catchment. J Hydrol 274(1-4):109-128

Uehlinger U, Malard F (2003) Ecology of a glacial flood plain. In: Aquatic ecology series. Kluwer Academic Publishers, Dordrecht, pp 75-90

Uehlinger U, Maisch M, Rothenbühler C, Zah R (2003) Val Roseg: a high alpine catchment. In: Ecology of a glacial flood plain. Springer, New York, pp 1-16

Ward JV (2004) Aquatic insect ecology. Part 1. In: Biology and habitat. Wiley, New York

WGMS (World Glacier Monitoring Service) (2009) Glacier mass balance. Bulletin No. 10 (2006-2007), Zürich 